\title{
Obstructive Sleep Apnea Syndrome as an Important Risk Factor in Severe Covid-19 Disease
}

\author{
Calixto Machado ${ }^{1 *}$, Phillip A DeFina ${ }^{2}$, Yanín Machado ${ }^{1}$, Mauricio Chinchilla ${ }^{1}$, Elena Cuspineda and \\ Yazmina Machado ${ }^{1}$ \\ ${ }^{1}$ Institute of Neurology and Neurosurgery, Havana, Cuba \\ ${ }^{2}$ CEO of the International Brain Research Foundation, New York, USA

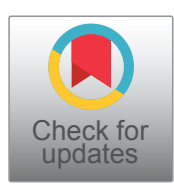

\begin{abstract}
OSAS has been considered by some authors an important risk factor for severe Covid-19. Risk factors for mortality in COVID-19, such as cardiovascular and cerebrovascular complications or comorbidities, for example hypertension, heart failure, coronary artery disease, cerebrovascular diseases, diabetes mellitus, and obesity are commonly seen in OSAS patients. SARS-CoV-2 uses the ACE2 receptor for host cell entry, and augmented expression of ACE and dysregulation of the renin-angiotensin system in untreated OSAS patients, due to chronic intermittent hypoxia, has been shown. Angiotensin converting enzyme (ACE) abnormalities have been implicated in the pathogenesis of cardiovascular and cerebrovascular diseases. Therefore, it is suspected that OSAS (particularly with concurrent obesity) could potentially contribute to worsening hypoxemia leading to the cytokine storm that typically occurs in patients with COVID-19, which can cause acute respiratory distress syndrome (ARDS) and multiorgan failure. Happy or silent hypoxemia in OSAS patients can even induce more confusion to clinicians in patients who can speedily jump clinical evolution stages and suffer ARDS. Evolving evidence has shown that Non-Invasive Ventilation (NIV) may have a more significant and helpful role than firstly thought, mainly if it is used in an early phase of Covid-19, when the first respiratory symptoms appear. CPAP is nowadays the preferred form of NIV in the management of the hypoxemic COVID-19 patient. With improved and enhanced CPAP equipment, there is now growing evidence that it may be of benefit to patients early in the disease process, may prevent deterioration to ARDS reducing the need for invasive ventilation at all.
\end{abstract}

\section{Keywords}

Covid-19, Obstructive sleep apnea syndrome (OSAS), SARS-CoV-2, Acute respiratory distress syndrome (ARDS), Noninvasive ventilation, CPAP

\section{Introduction}

According the recent publications, agedness, hypertension, cardiovascular diseases, lung diseases, and diabetes mellitus seem to be the main risk factors for mortality in COVID-19 [1-10]. Nevertheless, publications about the possible association between obstructive sleep apnea syndrome (OSAS) and COVID-19 are relatively scarce [11-15].

OSAS has been considered by some authors an important risk factor for severe Covid-19 $[16,17]$. The prevalence of several cardiovascular diseases is increased with OSAS with still unclear reasons. Bhatraju, et al. evaluated 24 patients with COVID-19 in an ICU in Washington State, and they revealed that $21 \%$ had OSA [18]. Additionally, Arentz, et al. evaluated 21 patients with COVID-19 in an ICU and observed that $28.6 \%$ complained [19].

Risk factors for mortality in COVID-19, such as cardiovascular and cerebrovascular complications or comorbidities, for example hypertension, heart failure, coronary artery disease, cerebrovascular diseases, diabetes mellitus, and obesity are commonly seen in OSAS patients [4,9,20-22]. Fibrotic changes can also be seen after COVID-19, and fibrosis was previously shown to be a risk factor for OSAS [23].

Worth mentioning, the augmented expression of ACE and dysregulation of renin-angiotensin system in untreated OSAS patients due to chronic intermittent hypoxia has been shown. Angiotensin converting enzyme (ACE) abnormalities have been implicated in the pathogenesis of cardiovascular

*Corresponding author: Calixto Machado, MD, Ph.D., FAAN, Institute of Neurology and Neurosurgery Department of Clinical Neurophysiology 29 y D, Vedado La Habana 10400 Cuba

Accepted: December 21, 2020

Published online: December 23, 2020

Citation: Machado C, DeFina PA, Machado Y, et al. (2020) Obstructive Sleep Apnea Syndrome as an Important Risk Factor in Severe Covid-19 Disease. J Clin Anesth Pain Manag 4(2):150-155 
and cerebrovascular diseases [24-27].

SARS-CoV-2 uses the ACE2 receptor for host cell entry. The angiotensin converting enzyme (ACE) is a zinc metallo-peptidase, whose main functions are to convert angiotensin I into angiotensin II (a vasoactive peptide) and to inactivate bradykinin. Because of its effects upon vascular tone and the formation of the atherosclerotic plaque, alterations in ACE production have been implicated in the pathogenesis of various cardiovascular and cerebrovascular diseases [28-30].

Barcelo, et al. concluded that the plasma activity of ACE is significantly increased in patients with untreated OSAS, which is independent of the presence of arterial hypertension. These authors ruled out that different genotype distributions can result in different ACE activity levels, because no different distribution or allelic frequency was found between OSAS patients and healthy subjects [31].

OSAS leads to repetitive airway collapse with apnea/hypopnea and hypoxia during sleep. It is important to emphasize that these episodes of hypoxia/reoxygenation that occur during each episode of apnea in OSAS patients can stimulate the synthesis of ACE in endothelial cells, inducing a higher ACE activity, contributing to the increased prevalence of cardiovascular and cerebrovascular diseases reported in OSAS patients [31,32].

Therefore, it is suspected that OSAS (particularly with concurrent obesity) could potentially contribute to worsening hypoxemia and the cytokine storm that occurs in patients with COVID-19. Obesity likely contributes to hypoxemia by reducing end-expiratory lung volume and by contributing to positive pleural pressures at end-exhalation. Both OSAS and obesity hypoventilation can cause important hypoxemia, which could worsen hypoxemia in COVID-19 pneumonia. Additionally, both OSAS and obesity could exacerbate the cytokine storm that can happen in with SARS-CoV-2 infection, which can cause acute respiratory distress syndrome (ARDS) and multiorgan failure, given that both OSAS and obesity may be proinflammatory conditions [33-37].

OSAS has been found to be an independent risk factor for post-obstructive pulmonary edema in patients requiring tracheostomy $[38,39]$. Patients with OSAS requiring surgery have been shown to have a higher rate of pulmonary complications with hypoxemia being most common, even following adjustment for body mass index [40-43].

Clinicians must consider the diagnosis of OSAS in Covid-19 patients. A simple questionnaire, without the needs for a polysomnography study, might give a high level of confidence that that the patient is complaining OSAS [44-48].

OSAS patients may experience such alterations in pulmonary mechanics as airflow obstruction, decreased lung volumes, and impaired gas exchange, all of which may predispose them to develop ARDS [49].

Our hypothesis is that episodes of sleep apnea in Covid-19 patients can provoke a speedy progress to acute distress respiratory syndrome (ARDS), requiring mechanical ventilation [50-52].

\section{Acute Respiratory Distress Syndrome and Happy or Silent Hypoxemia in Covid-19 Patients Complaining OSAS}

The most characteristic and challenging symptoms of Covid-19 are related to acute respiratory distress syndrome (ARDS) [53-56]. Wang, et al. reported that about $46 \%$ to $65 \%$ of the patients admitted in the intensive care units (ICUs) required mechanical ventilation in a brief period of time and died because of respiratory distress. According to these data, about $89 \%$ of the patients in intensive care units (ICUs) could not breathe by their own, worsening in a short period of time and dying due to respiratory failure $[2,57]$. ARDS remains a common cause of respiratory failure in ICUs with estimated mortality rate of over $40 \%$ [50].

Moreover, one of the aspects perplexing clinicians who take care of COVID-19 patients with pronounced arterial hypoxemia yet without proportional signs of respiratory distress, with even deceiving cyanosis, is that they don't even express a sense of dyspnea. Nonetheless, these patients very frequently rapidly progress to ARDS, requiring mechanical ventilation. This phenomenon is referred as silent or "happy or silent hypoxemia" [58-62].

For clinicians the presence of happy or silent hypoxemia in Covid-19 patients, in spite of pronounced arterial hypoxemia, can erroneously lead to the conclusion that the patient is not in a critical condition. Those cases can quickly leapfrog clinical evolution stages and suffer ARDS, with concomitant cardiorespiratory arrest and death $[63,64]$.

Hence, happy or silent hypoxemia in OSAS patients can even induce more confusion to clinicians in patients who can speedily jump clinical evolution stages and suffer ARDS $[50,63,64]$.

Pulse oximetry which measures oxygen saturation $\left(\mathrm{SpO}_{2}\right)$ is often used to detect hypoxemia. Nevertheless, $\mathrm{SpO}_{2}$ should be carefully interpreted in COVID-19. The sigmoid shaped oxyhemoglobin dissociation curve seems to shift to the left, due to induced respiratory alkalosis (drop in $\mathrm{PaCO}_{2}$ ) because of hypoxemia-driven tachypnea and hyperpnea. During hypocapnic periods, the affinity of hemoglobin for oxygen and thus oxygen saturation rises for a specified degree of $\mathrm{PaO}_{2}$, explaining why $\mathrm{SpO}_{2}$ can be well-preserved in the face of a profoundly low $\mathrm{PaO}_{2}$. In high altitude hypoxemia, hypocapnia significantly changes the oxygen-hemoglobin dissociation curve and recovers blood oxygen saturation. The alveolar gas equation also predicts that hyperventilation and the resulting drop in the alveolar partial pressure of $\mathrm{CO}_{2}$ produces an increment in the alveolar partial pressure of oxygen and finally lead to a raise in $\mathrm{SpO}_{2}[50,59,63,65,66]$.

\section{Invasive or Non-Invasive Ventilation in Covid-19 Patients}

Over the past decade, the use of noninvasive ventilation (NIV) in the setting of acute exacerbations of chronic obstructive pulmonary disease has gained popularity [67-69]. The treatment for severe respiratory failure in Covid-19 patients have included early intubation and invasive ventilation, 
as this was deemed preferable to be more effective than Non-Invasive Ventilation (NIV). Nevertheless, evolving evidence has shown that NIV may have a more significant and helpful role than firstly thought, mainly if it is used in an early phase of the disease when the first respiratory symptoms appear. NIV avoids the need for sedation, allows easier communication with patient, and requires less intensive nursing care $[16,67,70,71]$.

There are three types of NIV: High Flow Nasal Oxygen (HFNO), Continuous Positive Airway Pressure (CPAP) and BiPAP (Bi-Level Positive Airway Pressure) [67].

\section{High flow nasal oxygen (HFNO)}

HFNO therapy through a nasal cannula is a technique whereby heated and humidified oxygen is delivered to the nose at high flow rates. These high flow rates generate low levels of positive pressure in the upper airways, and the fraction of inspired oxygen $\left(\mathrm{FiO}_{2}\right)$ can be attuned by varying the fraction of oxygen in the driving gas. The high flow rates may also reduce physiological dead space by flushing expired $\mathrm{CO}_{2}$ from the upper airway, a process that possibly explains the observed decrement in the process of breathing. In patients with acute respiratory failure of various origins, high-flow oxygen has been shown to result in better comfort and oxygenation than standard oxygen therapy delivered through a face mask [71,72].

Nonetheless, the use of HFNO remains controversial in suspected and confirmed severe cases of COVID-19 disease. As a result, currently in the UK, the national guidance does not recommend HFNO in COVID-19 because for the lack of evidence of efficacy, the high oxygen usage, and risk of infection spread [71,73-75].

\section{Bilevel positive airway pressure (BiPAP)}

BiPAP is commonly used in the care of patients with chronic respiratory disease, so it may be useful in COVID-19 patients. In COVID-19, BiPAP may have a clinical use to improve the work of breathing. However, it carries a risk that inappropriate settings may allow the patient to take an excessively large tidal volume causing baro and volutrauma. BiPAP allows for a high driving pressure coupled with a low driving pressure. Prior to commencing BiPAP, the patient must be assessed for a pneumothorax, ideally by a chest X-Ray or ultrasound. Due to the need for chest auscultation for COVID-19 patients, is not recommended as it increases the risk of transmission to the healthcare professional [75-77].

\section{Continuous positive airway pressure (CPAP)}

CPAP is nowadays the preferred form of NIV in the management of COVID-19 patients. With improved and enhanced CPAP equipment, there is now growing evidence that it may be of benefit to patients early in the disease process, may prevent deterioration and reduce the need for invasive ventilation at all.

CPAP is usually commenced at a higher level than normal intrinsic pressure around $5 \mathrm{cmH}_{2} \mathrm{O}$. For most patients with ARDS, it is secondary to conditions which either collapse the alveolar or widen the gap between the alveolar and the blood vessels that surround them thereby reducing gaseous exchange. The application of Positive End Expiratory Pressure (PEEP) assists in maintaining the patient's airway pressure prevents alveolar collapse, in turn increasing lung volumes and distends them to reduce the distance between the alveolar and the blood vessels to improve gaseous exchange. In severe COVID-19, initial CPAP settings have been suggested $10 \mathrm{cmH}_{2} \mathrm{O}$ and $60 \%$ oxygen $[12,15,73,74,77-82]$.

It is also recommended to early use CPAP in all Covid-19 patient, even without complaining OSAS, when the first respiratory symptoms appear, such as cough, or light tachypnea and hyperpnea, etc., when they are still outside the ICUs, i.e. in regular wards or at patient's homes. This method would prevent periods of hypopnea and hypoxia which can stimu-

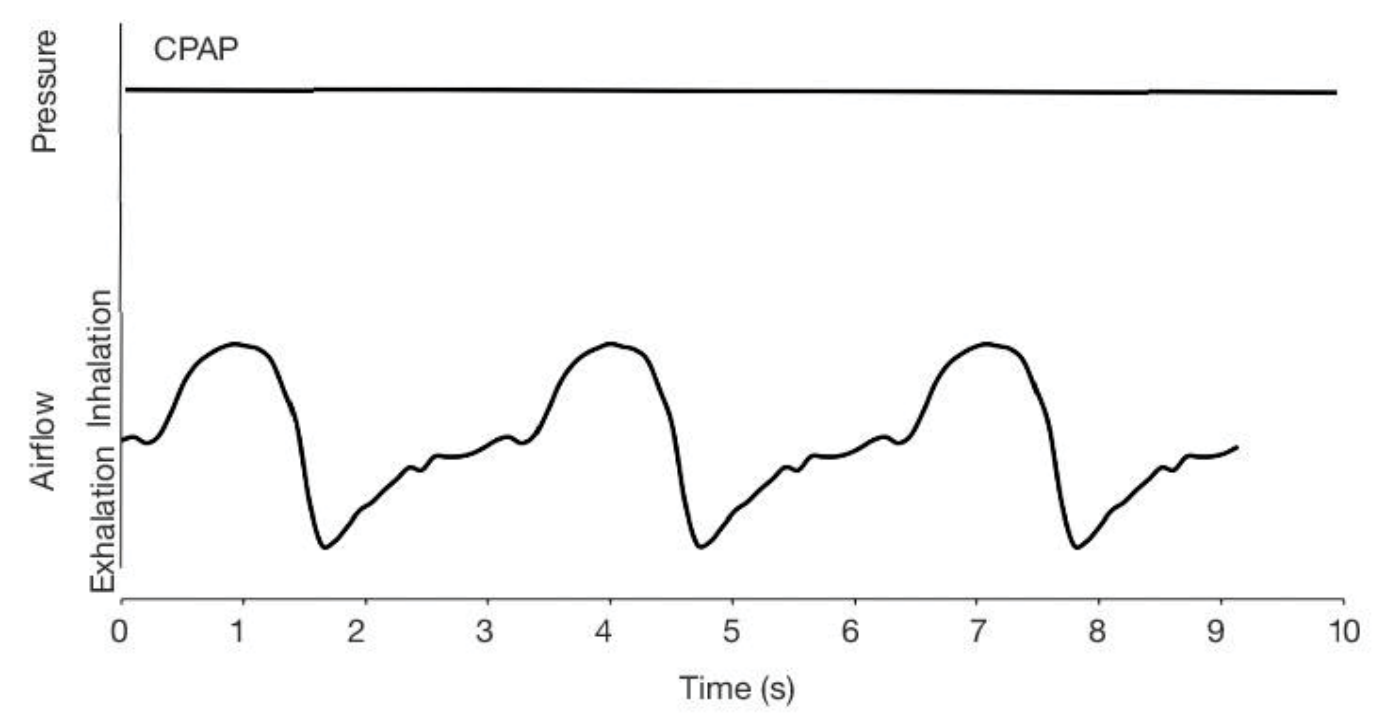

Figure 1: CPAP (continuous positive air pressure) methodology allows a normal and regular airflow eliminating the presence or sleep apneas. 


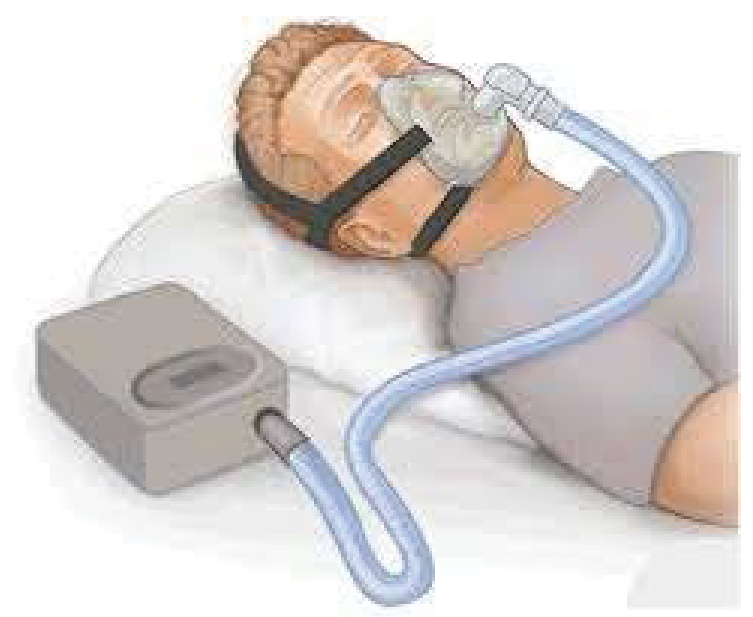

Figure 2: Commercially available CPAP machines can be used to treat Covid-19 patients in regular wards or at patients' homes.

late the synthesis of ACE in endothelial cells, finally leading to cytokine storm, which can cause ARDS and multiorgan failure $[50,73,74,77,79,80]$ (Figure 1 and Figure 2).

\section{Conclusion}

1. OSAS should be considered as an important risk factor for severe Covid-19.

2. Clinicians must consider the diagnosis of OSAS in Covid-19 patients. A simple questionnaire, without the needs for a polysomnography study, might give a high level of confidence that the Covid-19 patient is complaining OSAS.

3. Clinicians should suspect the possibility of happy or silent hypoxemia presence, even with $\mathrm{SpO}_{2}$ normal values, measured by pulse oximeter. $\mathrm{SpO}_{2}$ can be well-preserved in the face of a profoundly low $\mathrm{PaO}_{2}$. It is important to remark that patients with happy or silent hypoxemia don't express sense of dyspnea.

4. NIV using CPAP must be used very early in OSAS patients, not only in ICUs, but in regular wards or at patient's homes.

5. We also recommend to early use CPAP in any Covid-19 patient, even without complaining OSAS, when the first respiratory symptoms appear, such as cough, or even light tachypnea and hyperpnea, etc., even outside ICUs, i.e. in regular wards or at patient's homes.

\section{References}

1. Al-Shamsi HO, Alhazzani W, Alhuraiji A, et al. (2020) A practical approach to the management of cancer patients during the novel coronavirus disease 2019 (COVID-19) pandemic: An International Collaborative Group. Oncologist 25: e936-e945.

2. Wang L, He W, Yu X, et al. (2020) Coronavirus disease 2019 in elderly patients: Characteristics and prognostic factors based on 4-week follow-up. J Infect 80: 639-645.

3. Chen T, Wu D, Chen H, et al. (2020) Clinical characteristics of 113 deceased patients with coronavirus disease 2019: Retrospective study. BMJ 368.
4. Wu C, Chen X, Cai Y, et al. (2020) Risk factors associated with acute respiratory distress syndrome and death in patients with coronavirus disease 2019 pneumonia in Wuhan, China. JAMA Intern Med 180: 934-943.

5. Merkler AE, Parikh NS, Mir S, et al. (2020) Risk of ischemic stroke in patients with coronavirus disease 2019 (COVID-19) vs patients with influenza. JAMA Neurol 77: 1-7.

6. Archie SR, Cucullo L (2020) Cerebrovascular and neurological dysfunction under the threat of COVID-19: Is there a comorbid role for smoking and vaping? Int J Mol Sci 21: 3916.

7. Ni MY, Yang L, Leung CMC, et al. (2020) Mental health, risk factors, and social media use during the COVID-19 epidemic and cordon sanitaire among the community and health professionals in Wuhan, China: Cross-sectional survey. JMIR Ment Health 7: e19009.

8. Mueller AL, McNamara MS, Sinclair DA (2020) Why does COVID-19 disproportionately affect older people? Aging (Albany NY) 12: 9959-9981.

9. Lippi G, Wong J, Henry BM (2020) Hypertension in patients with Coronavirus Disease 2019 (COVID-19): A pooled analysis. Pol Arch Intern Med 130: 304-309.

10. Yan $Y$, Yang $Y$, Wang F, et al. (2020) Clinical characteristics and outcomes of patients with severe covid-19 with diabetes. BMJ Open Diabetes Res Care 8.

11. Cade BE, Dashti HS, Hassan SM, et al. (2020) Sleep apnea and COVID-19 mortality and hospitalization. Am J Respir Crit Care Med 202: 1462-1464.

12. Thorpy M, Figuera-Losada M, Ahmed I, et al. (2020) Management of sleep apnea in New York City during the COVID-19 pandemic. Sleep Medicine 74: 86-90.

13. Ekiz T, Inonu KH, Pazarli AC (2020) Obstructive sleep apnea, renin-angiotensin system, and COVID-19: Possible interactions. J Clin Sleep Med 16: 1403-1404.

14. Gulbay B, Azap A, Kaya A, et al. (2020) Management of obstructive sleep apnea during COVID-19 pandemic. Tuberk Toraks 68: 135-140.

15. Nakano H, Kadowaki M, Furukawa T, et al. (2020) Rise in nocturnal respiratory rate during CPAP may be an early sign of COVID-19 in patients with obstructive sleep apnea. J Clin Sleep Med 16: 1811-1813.

16. Suen CM, Hui DSC, Memtsoudis SG, et al. (2020) Obstructive sleep apnea, obesity, and noninvasive ventilation: Considerations during the COVID-19 pandemic. Anesth Analg 131: 318322.

17. Salles C, Mascarenhas Barbosa H (2020) COVID-19 and obstructive sleep apnea. J Clin Sleep Med 16: 1647.

18. Bhatraju PK, Ghassemieh BJ, Nichols M, et al. (2020) Covid-19 in critically III patients in the Seattle region - case series. N Engl J Med 382: 2012-2022.

19. Arentz M, Yim E, Klaff L, et al. (2020) Characteristics and outcomes of 21 critically III patients with COVID-19 in Washington State. JAMA 323: 1612-1614.

20. Manne-Goehler J, Atun R, Stokes A, et al. (2016) Diabetes diagnosis and care in sub-Saharan Africa: Pooled analysis of individual data from 12 countries. Lancet Diabetes Endocrinol 4: 903-912.

21. Grasselli G, Zangrillo A, Zanella A, et al. (2020) Baseline characteristics and outcomes of 1591 patients infected with SARS- 
CoV-2 admitted to ICUs of the Lombardy Region, Italy. JAMA 323: 1574-1581.

22. Guo T, Fan Y, Chen M, et al. (2020) Cardiovascular implications of fatal outcomes of patients with Coronavirus Disease 2019 (COVID-19). JAMA Cardiol 5: 811-818.

23. Whyte CS, Morrow GB, Mitchell JL, et al. (2020) Fibrinolytic abnormalities in acute respiratory distress syndrome (ARDS) and versatility of thrombolytic drugs to treat COVID-19. J Thromb Haemost 18: 1548-1555.

24. Pazarli AC, Ekiz T, llik F (2020) Coronavirus disease 2019 and obstructive sleep apnea syndrome. Sleep Breath.

25. Cicolin A, Mangiardi L, Mutani R, et al. (2006) Angiotensin-converting enzyme inhibitors and obstructive sleep apnea. Mayo Clin Proc 81: 53-55.

26. Prisant LM, Dillard TA, Blanchard AR (2006) Obstructive sleep apnea syndrome. J Clin Hypertens (Greenwich) 8: 746-750.

27. Rubinsztajn R, Kumor M, Byskiniewicz K, et al. (2004) Angiotensin-converting enzyme gene polymorphism in patients with obstructive sleep apnea. Pol Arch Med Wewn 112: 817-822.

28. Buzhdygan TP, DeOre BJ, Baldwin-Leclair A, et al. (2020) The SARS-CoV-2 spike protein alters barrier function in 2D static and $3 \mathrm{D}$ microfluidic in vitro models of the human blood-brain barrier. Neurobiology of Disease 146: 105131.

29. Guo J, Wei X, Li Q, et al. (2020) Single-cell RNA analysis on ACE2 expression provides insights into SARS-CoV-2 potential entry into the bloodstream and heart injury. J Cell Physiol 235: 98849894.

30. Hussain M, Jabeen N, Raza F, et al. (2020) Structural variations in human ACE2 may influence its binding with SARS-CoV-2 spike protein. J Med Virol 92: 1580-1586.

31. Barcelo A, Elorza MA, Barbe F, et al. (2001) Angiotensin converting enzyme in patients with sleep apnoea syndrome: Plasma activity and gene polymorphisms. Eur Respir J 17: 728-732.

32. Alobid I, Cardelus S, Benitez P, et al. (2011) Persistent asthma has an accumulative impact on the loss of smell in patients with nasal polyposis. Rhinology 49: 519-524.

33. Ekiz T, Pazarli AC (2020) Relationship between COVID-19 and obesity. Diabetes Metab Syndr 14: 761-763.

34. Lui B, Samuels JD, White RS (2020) Potential pathophysiology of COVID-19 in patients with obesity. Comment on $\mathrm{Br} J$ Anaesth 2020; 125: e262-e263. Br J Anaesth 125: e283-e284.

35. McSharry D, Malhotra A (2020) Potential influences of obstructive sleep apnea and obesity on COVID-19 severity. J Clin Sleep Med 16: 1645.

36. Memtsoudis SG, Ivascu NS, Pryor KO, et al. (2020) Obesity as a risk factor for poor outcome in COVID-19-induced lung injury: The potential role of undiagnosed obstructive sleep apnoea. $\mathrm{Br} J$ Anaesth 125: e262-e263.

37. Scheen AJ (2020) Obesity and risk of severe COVID-19. Rev Med Suisse 16: 1115-1119.

38. McGrath BA, Pelosi P, Schultz MJ, et al. (2020) Preoperative apnea trial and considerations regarding timing of tracheostomy in anesthetic planning for patient with COVID-19 disease. J Clin Anesth 67: 110013.

39. Niroula A, Van Nostrand KM, Khullar OV, et al. (2020) Percutaneous tracheostomy with apnea during coronavirus disease
2019 Era: A protocol and brief report of cases. Crit Care Explor 2: e0134.

40. Albashir AAD (2020) The potential impacts of obesity on COVID-19. Clin Med (Lond) 20: e109-e113.

41. Anand A, Kumar R, Shalimar (2020) Obesity and mortality in COVID-19: Cause or association? Gastroenterology.

42. Caci G, Albini A, Malerba M, et al. (2020) COVID-19 and obesity: Dangerous liaisons. J Clin Med 9: 2511.

43. Chiappetta S, Sharma AM, Bottino V, et al. (2020) COVID-19 and the role of chronic inflammation in patients with obesity. Int J Obes (Lond) 44: 1790-1792.

44. Thurtell MJ, Bruce BB, Rye DB, et al. (2011) The Berlin questionnaire screens for obstructive sleep apnea in idiopathic intracranial hypertension. J Neuroophthalmol 31: 316-319.

45. Apfelbacher C, Brandstetter S, Blecha S, et al. (2020) Influence of quality of intensive care on quality of life/return to work in survivors of the acute respiratory distress syndrome: Prospective observational patient cohort study (DACAPO). BMC Public Health 20: 861.

46. Traaen GM, Overland B, Aakeroy L, et al. (2020) Prevalence, risk factors, and type of sleep apnea in patients with paroxysmal atrial fibrillation. Int J Cardiol Heart Vasc 26: 100447.

47. Vaz AP, Drummond M, Mota PC, et al. (2011) Translation of Berlin questionnaire to Portuguese language and its application in OSA identification in a sleep disordered breathing clinic. Rev Port Pneumol 17: 59-65.

48. Srijithesh PR, Shukla G, Srivastav A, et al. (2011) Validity of the Berlin questionnaire in identifying obstructive sleep apnea syndrome when administered to the informants of stroke patients. J Clin Neurosci 18: 340-343.

49. Karnatovskaia LV, Lee AS, Bender SP, et al. (2014) Obstructive sleep apnea, obesity, and the development of acute respiratory distress syndrome. J Clin Sleep Med 10: 657-662.

50. Machado C (2020) Severe Covid-19 cases: Is respiratory distress partially explained by central nervous system involvement? MEDICC Rev 22: 38-39.

51. Machado C (2020) Reader response: Neurologists and COVID-19: A note on courage in a time of uncertainty. Neurology.

52. Machado C, Gutierrez JV (2020) Brainstem dysfunction in SARSCOV2 infection can be a potential cause of respiratory distress. Preprints.

53. Cao Y, Liu X, Xiong L, et al. (2020) Imaging and clinical features of patients with 2019 novel coronavirus SARS-CoV-2: A systematic review and meta-analysis. J Med Virol 92: 1449-1459.

54. Gattinoni L, Coppola S, Cressoni M, et al. (2020) Covid-19 does not lead to a "Typical" acute respiratory distress syndrome. Am J Respir Crit Care Med 201: 1299-1300.

55. Zhou M, Zhang X, Qu J (2020) Coronavirus disease 2019 (COVID-19): A clinical update. Front Med, 1-10.

56. Huang C, Wang Y, Li X, et al. (2020) Clinical features of patients infected with 2019 novel coronavirus in Wuhan, China. Lancet 395: 497-506.

57. Wang J, Hajizadeh N, Moore EE, et al. (2020) Tissue plasminogen activator (tPA) treatment for COVID-19 associated acute respiratory distress syndrome (ARDS): A case series. J Thromb Haemost 18: 1752-1755. 
58. Couzin-Frankel J (2020) The mystery of the pandemic's 'happy hypoxia'. Science 368: 455-456.

59. Dhont S, Derom E, Van Braeckel E, et al. (2020) The pathophysiology of 'happy' hypoxemia in COVID-19. Respir Res 21: 198.

60. Gonzalez-Duarte A, Norcliffe-Kaufmann L (2020) Is 'happy hypoxia' in COVID-19 a disorder of autonomic interoception? A hypothesis. Clin Auton Res 30: 331-333.

61. Jounieaux V, Rodenstein DO, Mahjoub Y (2020) On happy hypoxia and on sadly ignored "acute vascular distress syndrome" in COVID-19 patients. Am J Respir Crit Care Med 202: 1598-1599.

62. Sahu D, Agrawal T (2020) Is it the COVID-19 happy hypoxia syndrome or the COVID 19 infodemic syndrome? Diabetes Metab Syndr 14: 1399.

63. Tobin MJ, Laghi F, Jubran A (2020) Why COVID-19 silent hypoxemia is baffling to physicians. Am J Respir Crit Care Med 202: 356-360.

64. U RA, Verma K (2020) Happy hypoxemia in COVID-19-a neural hypothesis. ACS Chem Neurosci 11: 1865-1867.

65. Luks AM, Swenson ER (2020) Pulse oximetry for monitoring patients with COVID-19 at home: Potential pitfalls and practical guidance. Ann Am Thorac Soc 17: 1040-1046.

66. Quaresima V, Ferrari M (2020) COVID-19: Efficacy of prehospital pulse oximetry for early detection of silent hypoxemia. Crit Care 24: 501.

67. Alraddadi BM, Qushmaq I, Al-Hameed FM, et al. (2019) Noninvasive ventilation in critically ill patients with the Middle East respiratory syndrome. Influenza Other Respir Viruses 13: 382-390.

68. Pirzada AR, Aleissi SA, Almeneessier AS, et al. (2020) Management of Aerosol during noninvasive ventilation for patients with sleep-disordered breathing: Important messages during the COVID-19 pandemic. Sleep Vigil, 1-6.

69. Sartini C, Tresoldi M, Scarpellini P, et al. (2020) Respiratory parameters in patients with COVID-19 after using noninvasive ventilation in the prone position outside the intensive care unit. JAMA 323: 2338-2340.

70. Qin C, Zhou L, Hu Z, et al. (2020) Clinical characteristics and outcomes of COVID-19 patients with a history of stroke in Wuhan, China. Stroke 51: 2219-2223.

71. Wang K, Zhao W, Li J, et al. (2020) The experience of high-flow nasal cannula in hospitalized patients with 2019 novel corona- virus-infected pneumonia in two hospitals of Chongqing, China. Ann Intensive Care 10: 37.

72. Akbarian-Rad Z, Mohammadi A, Khafri S, et al. (2020) Comparison of heated humidified high flow nasal cannula and nasal continuous positive airway pressure after surfactant administration in preterm neonates with respiratory distress syndrome. Clin Respir J 14: 740-747.

73. Czajkowska-Malinowska M, Kania A, Kuca PJ, et al. (2020) Treatment of acute respiratory failure in the course of COVID-19. Practical hints from the expert panel of the assembly of intensive care and rehabilitation of the Polish respiratory society. Adv Respir Med 88: 245-266.

74. Perkins GD, Couper K, Connolly B, et al. (2020) RECOVERY- respiratory support: Respiratory strategies for patients with suspected or proven COVID-19 respiratory failure; continuous positive airway pressure, high-flow nasal oxygen, and standard care: A structured summary of a study protocol for a randomised controlled trial. Trials 21: 687.

75. Whittle JS, Pavlov I, Sacchetti AD, et al. (2020) Respiratory support for adult patients with COVID-19. J Am Coll Emerg Physicians Open 1: 95-101.

76. Chiner E, Canovas C, Molina V, et al. (2020) Home respiratory polygraphy is useful in the diagnosis of childhood obstructive sleep apnea syndrome. J Clin Med 9: 2067.

77. Rali AS, Howard C, Miller R, et al. (2020) Helmet CPAP revisited in COVID-19 pneumonia: A case series. Can J Respir Ther 56: 32-34.

78. Baker JG, Sovani M (2020) Case for continuing community NIV and CPAP during the COVID-19 epidemic. Thorax 75: 368.

79. Barker J, Oyefeso O, Koeckerling D, et al. (2020) COVID-19: community CPAP and NIV should be stopped unless medically necessary to support life. Thorax 75: 367.

80. Mwenge GB, Rodenstein D (2020) CPAP added to oxygen administration avoid intubation in acute respiratory distress in COVID-19 pneumonia. Case Report. SN Compr Clin Med, 1-4.

81. Pirzada A, Awadh AA, Aleissi SA, et al. (2020) Reopening sleep medicine services in the conundrum of an ongoing COVID-19 pandemic: A global view. Sleep Vigil, 1-8.

82. Bastier PL, Aisenberg N, Durand F, et al. (2020) Treatment of sleep apnea by ENT specialists during the COVID-19 pandemic. Eur Ann Otorhinolaryngol Head Neck Dis 137: 319-321.

DOI: $10.36959 / 377 / 347$

Copyright: (c) 2020 Machado C, et al. This is an open-access article distributed under the terms of the Creative Commons Attribution License, which permits unrestricted use, distribution, and reproduction in any medium, provided the original author and source are credited. 